\title{
DEFORESTATION POLYGON ASSESSMENT TOOL: PROVIDING COMPREHENSIVE INFORMATION ON DEFORESTATION IN THE BRAZILIAN CERRADO BIOME
}

\author{
Luiz Mário. L. Pascoal ${ }^{1 *}$ Leandro L. Parente ${ }^{1}$, Sérgio H. M. Nogueira ${ }^{1}$, Laerte Guimarães Ferreira Júnior ${ }^{1}$ \\ ${ }^{1}$ Image Processing and Geoprocessing Laboratory, Federal University of Goias, Goiania - Goias, Brazil - \\ (luizmlpascoal, leal.parente, serque)@gmail.com
}

Commission VI, WG VI/4

KEY WORDS: Web Geographic System, Deforestation, Assessment, Cerrado, PRODES-Cerrado, DETER-Cerrado

\begin{abstract}
:
Considered a conservation hotspot of the world biodiversity and a key region for the agriculture production in Brazil, the Cerrado biome has only $7.5 \%$ of its native vegetation as fully protected areas. Given this, in 2016 the Brazilian government started an official project to monitoring deforestation in the biome, through the so-called PRODES-Cerrado, responsible for mapping deforested areas from 2000 on, and DETER-Cerrado, responsible to generate deforestation alerts. Seeking to contribute with both context information and confidence levels for the polygons produced by these two monitoring systems, we developed the Deforestation Polygon Assessment Tool. This web-based platform process and presents several analysis for PRODES-Cerrado and DETERCerrado polygons using automatic assessments (e.g. BFastMonitor and Weights of Evidence), field validation and spatial analysis with key datasets (e.g. National Land Registry, Land-Use and Land-Cover maps). The platform implements an interactive map which allows a fast and comprehensive visualization of different layers, as well as a Deforestation Report at the polygon level, which gathers all the information about each polygon, providing greater reliability and understanding of the deforestation dynamics in the Cerrado. Future improvements in the platform will consider additional, spatial relations in order to assist government agencies to either prevent or reduce deforestation ocurrences in each municipality in the Cerrado biome.
\end{abstract}

\section{INTRODUCTION}

Remote sensing is an important and consolidated instrument to monitoring the territory at different scales and through various sensor systems (Hansen, Loveland, 2012). Regarding regional and national monitoring, Brazil has some pioneering initiatives that produced relevant and official data for the country (e.g. PROBID ${ }^{1}$ RADAM ${ }^{2}$ and PRODES-Amazon 3 . Cosidering that the Cerrado is the second largest Brazilian biome (Sano et al., 2008), with the largest flora biodiversity among all savannas in the world (Klink, Machado, 2005) and a key importance in the agriculture production in Brazil (Scaramuzza et al., 2017), the biome has only $7.5 \%$ of its native vegetation as fully protected areas (Strassburg et al., 2017). Given this, in 2016 the Brazilian government started a official project to monitoring deforestation in this biome, through the so-called PRODESCerrado and DETER-Cerrado systems. In addition to monitoring deforestation, this project, funded within the scope of the Forest Investment Program (FIP/World Bank), and currently in progress, also aims provide information about the risk of forest fires and to improve greenhouse gas estimation for the Cerrado biome (The World Bank, 2016).

The PRODES-Cerrado, responsible for mapping deforested areas from 2000 on, and DETER-Cerrado, responsible for generating deforestation alerts on a daily basis, were developed by the National Institute for Space Research-INPE, based on

\footnotetext{
*Corresponding author

1 https://www.mma.gov.br/biodiversidade/ projetos-sobre-a-biodiveridade/item/486-probio.html

${ }^{2}$ http://www.cprm.gov.br/publique/Geologia/

Sensoriamento-Remoto-e-Geofisica/RADAM-D-628.html

3 http://www.obt.inpe.br/OBT/assuntos/programas/ amazonia/prodes
}

the same methodology applied in the Amazon biome, that uses visual interpretation of satellite images (i.e. Landsat, ResourceSat and CBERS data) and vector editing (Diniz et al., 2015. Valeriano et al., 2004). These deforestation products are publicly available at Terrabrasilis 4 a web-based platform that organize and disseminate the spatial data from thematic maps produced by INPE (Assis et al., 2019).

As part of the same project, the Image Processing and GIS Laboratory at the Federal University of Goiás-LAPIG/UFG developed the Deforestation Polygon Assessment Tool-DPAT 5 , a web-based platform for estimating the uncertainty of polygons produced by PRODES-Cerrado and DETER-Cerrado, using independent and automated methods. The platform presents, for polygons detected after 2015, a context information (e.g. municipality and rural property) and a confidence level, established by the complementary approaches: field validation; sampling validation; and automatic deforestation assessment.

This study address the field validation, in Section 2 and the automatic deforestation assessment, in Section 3, since sample validation is still in progress and is not available on DPAT. The Section 4 presents the details of software architecture and the organized datasets, while the Section 5 cover the platform interface and its main functionality. Finally, a concluding remarks is presented about the potential uses of DPAT and the features that will be implemented in the future.

\section{FIELD VALIDATION}

The field validation considered four field routes, established in the regions with the most part of deforested areas and deforest-

\footnotetext{
${ }^{4}$ http://terrabrasilis.dpi.inpe.br/

${ }^{5}$ https://dpat.lapig.iesa.ufg.br/
} 
ation alerts from 2016, according to the PRODES-Cerrado and DETER-Cerrado. To capture a significant variability of conditions, we visited regions with different vegetation physiognomies, reliefs, soils and climatic and socioeconomic conditions. The electronic forms, GPS, drones, and cameras were used to validate a total of 367 deforestation polygons, of which 361 were anthropized. The most part of the visited areas were agriculture and pasture, but we found deforested areas without consolidated land use, with the presence of burnt woods and secondary vegetation.

\section{AUTOMATIC DEFORESTATION ASSESSMENT}

The automatic assessment considered the breakpoints detected by BFastMonitor (Verbesselt et al., 2012), using the NDVI time-series of MOD13Q1 (Huete et al., 2002), and the susceptibility of deforestation produced by Weight of Evidences, using the software Dinamica EGO (Soares-Filho et al., 2009) and 11 variables of influences (e.g. soil type, road distance).

\subsection{BFastMonitor}

Considering the Cerrado biome, the BfastMonitor presented a better breakpoint detection, associated with deforestation events, compared to Bfast01 and LandTrendR (Parente et al., 2018). As BfastMonitor depends on a complete NDVI timeseries (i.e. without gaps), we chose to use MOD13Q1 data, with a spatial resolution of $250 \mathrm{~m}$, to automatically evaluate the PRODES-Cerrado polygons. The observations obtained from 2000 to 2015 were used to modeling a future and stable NDVI serie, which was compared with the real observations obtained between 2016 and 2018. When the divergence between the two series was statistically significant, the method detected a breakpoint. We processed all MODIS pixels contained within the deforestation detected from 2015, totalizing 525,038 analysed pixels. Figure 1 a presents a deforestation detected by PRODESCerrado in 2017 and automatically confirmed by BfastMonitor. This deforestation occurred on a $13.99 \mathrm{~km}^{2}$ area, in the municipality of Benedito Leite-TO, and the deforestation polygon had 256 MODIS pixels, of which 237 had breakpoint detections. In 2018, we visited this area and saw clear signs of deforestation (e.g. cut and fallen woods, total absence of trees, and differences in vegetation structure relatively to neighboring areas - Figure 1p).

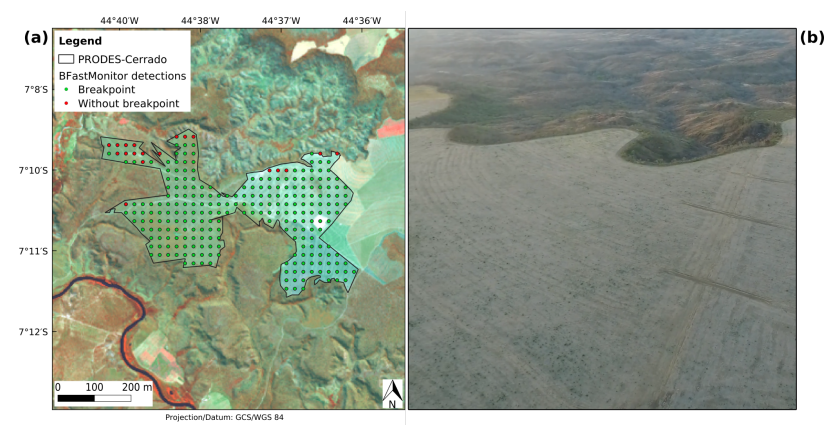

Figure 1. (a) The BFastMonitor result on a deforestation polygon of PRODES-Cerrado, in the municipality of Benedito Leite-TO. (b) Aerial image of the deforested area, obtained during the field validation in August 2018.

It is important to highlight that from the total of $21,869 \mathrm{~km}^{2}$ of deforested areas between 2016 and 2018 in the Cerrado biome,
BFastMonitor was able to confirm $15,550 \mathrm{~km}^{2}$, considering polygons that presented at least $50 \%$ of breakpoints in their time series, which represents almost $71 \%$ of the total deforested area. The rest of the deforested areas presented pixels with breakpoints, but with a lower proportion, which indicates that the BfastMonitor has difficulty to detect small deforestations (e.g. $0.25 \mathrm{~km}^{2}$ ) due to the resolution of the MODIS pixel. In general, there was a convergence between the results generated by the BFastMonitor and the data produced by PRODES-Cerrado.

\subsection{Weights of Evidence}

The susceptibility of deforestation surfaces was generated by the method Weights of Evidence, implemented in the platform Dinamica EGO, and considered the influence of the following variables: the distance from anthropogenic areas; road distance; distance from silos and warehouses; land tenure category; property size; texture and soil type; geomorphology; accumulated precipitation between 2000-2015, slope and altitude in deforestation areas between 2010 and 2015. The calibration of the method occurred using deforestation polygons detected from 2010 to 2015, and to capture better the trends and patterns of deforestation in the biome, two output results were produced: the susceptibility of large deforestation (i.e. $>=0.5 \mathrm{~km}^{2}-$ Figure $2 \mathrm{a}$ ) and the susceptibility of small deforestation (i.e. $<0.5$ $\mathrm{km}^{2}$ - Figure $2 \mathrm{~b}$ ). This area threshold (i.e. $0.5 \mathrm{~km}^{2}$ ) was chosen by a sensitivity analysis considering preliminary results of the Cerrado deforestation susceptibility (Nogueira et al., 2018).

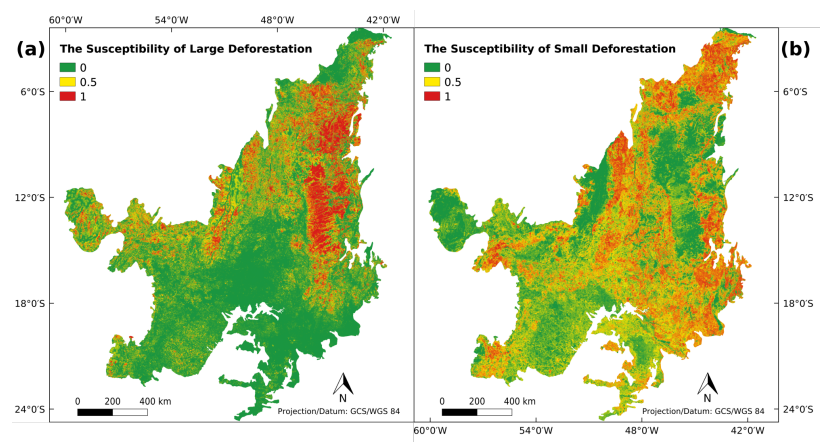

Figure 2. (a) The susceptibility of large deforestation (i.e. $>=0.5 \mathrm{~km}^{2}$ ). (b) The susceptibility of small deforestation (i.e. $<0.5 \mathrm{~km}^{2}$ )

These results were used to calculate a spatial mean of the deforestation susceptibility for each PRODES-Cerrado and DETERCerrado polygons, detected between 2015 and 2018. Regarding the PRODES-Cerrado, it was observed that approximately $51 \%$ of the polygons were in areas with susceptibility to large deforestation, the equivalent a $3,496 \mathrm{~km}^{2}$, and $75 \%$ of this area presented at least $50 \%$ of susceptibility. In the regions with susceptibility to small deforestation, which represents $59 \%$ of the total deforested area, $78.5 \%\left(3.851 \mathrm{~km}^{2}\right)$ had at least $50 \%$ of susceptibility. For the DETER-Cerrado only $14 \%$ of the polygons were located in regions with susceptibility to large deforestation, which comprised a total area of $2,855 \mathrm{~km}^{2}$ and representing approximately $54 \%$ of the all area encompassed by the alerts. Considering the DETER-Cerrado, polygons located in areas with susceptible of small deforestation, $71 \%$ had at least $50 \%$ of susceptibility. Although associated with the most common deforestation patterns and trends in the Cerrado biome, according with the calibration period (i.e. 2010 to 2015), the deforestation susceptibility data presented a good convergence with PRODES-Cerrado and DETER-Cerrado. 


\section{DEFORESTATION POLYGON ASSESSMENT TOOL}

Seeking to contribute to the continuous improvement of the detection process and to a better understanding of the dynamics related to deforestation in the Cerrado biome, we developed the Deforestation Polygon Assessment Tool-DPAT. This webbased platform is responsible for making publicly available several analyzes concerning the PRODES-Cerrado and DETERCerrado polygons, including the results of the field validation (e.g. geographic coordinates, photos and videos), the automatic assessments (e.g. BFastMonitor detections and the susceptibility of deforestation) and the spatial relation with other consolidated datasets such as the National Land Registry (Azevedo et al., 2017), TerraClass-Cerrado (Sano et al., 2019) and the Open Street Map (Foundation, 2019)).

\subsection{Software Architecture}

The architecture of DPAT, presented in the Figure 3 and based in other platforms developed by LAPIG/UFG (Silva et al., 2017), has seven software components, which are using several interoperability standards, defined by the Open Geospatial Consortium-OGC ${ }^{6}$ as Web Map Service-WMS, Simple Features SQL, GeoTIFF and GeoJSON (OGC, 2019).

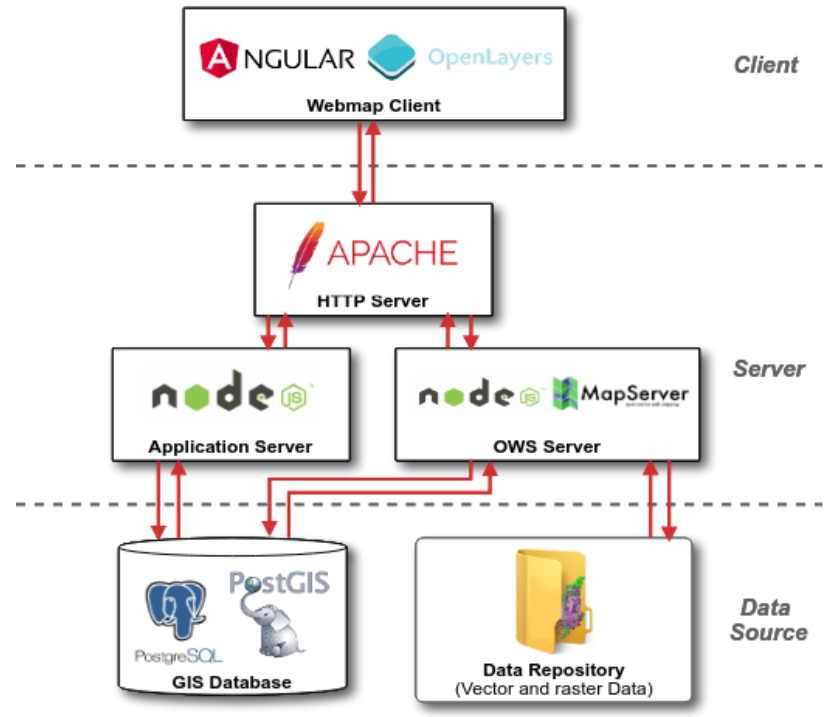

Figure 3. The software architecture of DPAT. The source code of the components is public available at www.github.com/lapig-ufg/d-pat

All the data used by DPAT is organized in a GIS Database, implemented in PostgreSQL, and Data Repository, implemented in a file structure. The database uses PostGIS extension, which adds support for storing and processing geographic data and enables spatial queries via Structured Query LanguageSQL. Geographic data that does not require spatial relation with PRODES-Cerrado and DETER-Cerrado polygons is stored in the data repository, in Shapefile and GeoTIFF formats.

This data is accessed by the Application Server, implemented in NodeJS, and by the OWS Server, implemented in NodeJS and Mapserver. The application Server is responsible for serving

\footnotetext{
${ }^{6}$ Open Geospatial Consortium is an international non-profit organization responsible to define and maintain standards that allow government agencies, Non-Governmental organizations, companies, academic and research institutions to share their geospatial data
}

alphanumeric data requests, usually related to charts or deforestation statistics (e.g. "Which municipality had the largest deforested area in 2017 ?" "What is the deforested area of some specific state ?"). The OWS Server is responsible for servicing requests involving geographic data, which are generally associated with OGC protocols. In fact, these requests are processed by MapServer, a free software with support for several data sources and capable of displaying spatial maps on the internet, so that the only role of NodeJS, in this component, is to organize a cache for the processed requests. All the WEB requests pass through the HTTP server, implemented in Apache. Finally, the Webmap Client is responsible for presenting and organizing all application data into visual components (e.g. interactive map, graphs, search fields), and was implemented in Angular, OpenLayer, Bootstrap, Material Design and PrimeNG.

\subsection{Datasets}

Aiming to provide a better characterization of PRODESCerrado and DETER-Cerrado polygons, we organized some key datasets from distinct sources in DPAT (Table 1). The consolidation of different datasets on a single platform facilitates the process of visualization and spatial analysis, traditionally performed on local GIS software (e.g. QuantumGIS and ArcGIS), in order to use our caching mechanism, implemented in the OWS Server component, reducing the response time of the geographic data requests. Specifically for the satellite data, we organized all Landsat images inspected by INPE in the PRODES-Cerrado system and produced 13 Landsat yearly mosaics, between 2000 and 2018, for the entire Cerrado biome (Figure 4 a). The same procedure was used to produce Sentinel 2 mosaics for 2016, 2017 and 2018, which have greater spatial resolution than the Landsat mosaics (i.e. $20 \mathrm{~m}$ spatial resolution - Figure 4p).

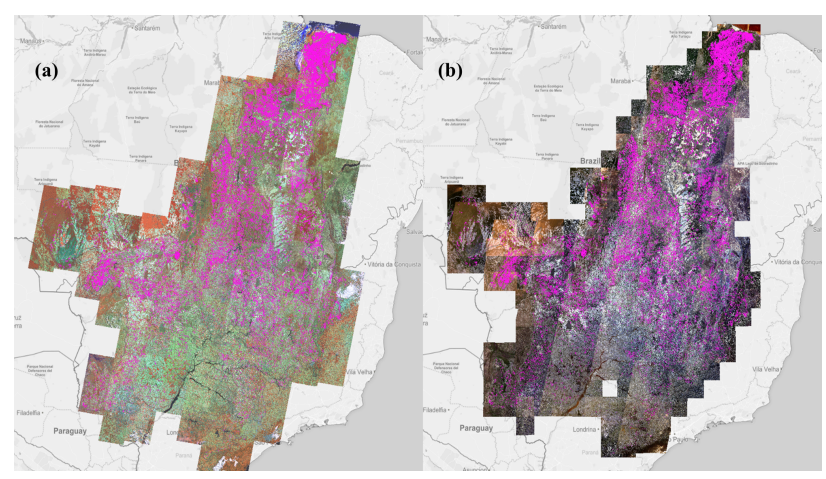

Figure 4. (a) PRODES-Cerrado deforestation polygons over the Landsat mosaic. (b) PRODES-Cerrado deforestation polygons over the Sentinel mosaics for the year of 2018.

\section{RESULTS AND DISCUSSIONS}

The main screen of DPAT, presented in figure 5, shows a interactive map centered in the Cerrado biome and four interactive boxes. The interactive box 1 is responsible to organize all datasets (table 1) in layers that can be added to the map, according with different filter options. By default, DPAT presents the PRODES-Cerrado layer, for 2018, but it is possible to choose other deforestation years and other layers, as DETER-Cerrado, the susceptibility of deforestation (section 3.2 ) or the Landsat and Sentinel mosaics. At the top, there is a search box that can be used to find a specific state or municipality. By selecting a state/municipality, the map zoom into that specific region 


\begin{tabular}{|c|c|c|}
\hline Category & Information Layer & Source \\
\hline \multirow{3}{*}{ Deforestation } & $\begin{array}{l}\text { PRODES- } \\
\text { Cerrado }\end{array}$ & INPE \\
\hline & $\begin{array}{l}\text { DETER - } \\
\text { Cerrado }\end{array}$ & INPE \\
\hline & $\begin{array}{l}\text { Susceptibility of } \\
\text { Deforestation }\end{array}$ & $\begin{array}{l}\text { LAPIG / } \\
\text { UFG }\end{array}$ \\
\hline \multirow{5}{*}{$\begin{array}{c}\text { Land-Use } \\
\text { and Land-Cover }\end{array}$} & $\begin{array}{c}\text { PRODES-Cerrado } \\
\text { Anthropic Mask (2015) }\end{array}$ & INPE \\
\hline & $\begin{array}{c}\text { Cerrado Land-Use } \\
\text { and Land-Cover (2013) }\end{array}$ & $\begin{array}{l}\text { TerraClass - } \\
\text { Cerrado } \\
\end{array}$ \\
\hline & $\begin{array}{c}\text { Cerrado Land-Use } \\
\text { and Land-Cover (2002) }\end{array}$ & $\begin{array}{l}\text { PROBIO - } \\
\text { Cerrado }\end{array}$ \\
\hline & $\begin{array}{c}\text { Annual crops } \\
(13 / 14)\end{array}$ & Agrosatelite \\
\hline & Planted Forests (2013) & $\begin{array}{l}\text { GFW - } \\
\text { WRI }\end{array}$ \\
\hline \multirow{3}{*}{ Infrastructure } & $\begin{array}{c}\text { Roads } \\
\text { (Federal/State) }\end{array}$ & $\begin{array}{l}\text { Open Street } \\
\text { Map }\end{array}$ \\
\hline & $\begin{array}{l}\text { Warehouse } \\
\text { Location }\end{array}$ & CONAB \\
\hline & Slaughterhouse & $\begin{array}{l}\text { LAPIG / } \\
\text { UFG }\end{array}$ \\
\hline \multirow{2}{*}{ Geophysical } & Altitude & \multirow{2}{*}{ SRTM } \\
\hline & $\begin{array}{l}\text { Declivity } \\
\text { Cumulative Precipitation }\end{array}$ & \\
\hline \multirow[t]{2}{*}{ Edaphoclimatic } & Average & TRMM/GPM \\
\hline & $\begin{array}{c}\text { Soils } \\
(1: 250.000) \\
\end{array}$ & IBGE \\
\hline \multirow{4}{*}{$\begin{array}{l}\text { National Land } \\
\text { Registry }\end{array}$} & Rural properties & \multirow{4}{*}{ SICAR } \\
\hline & $\begin{array}{l}\text { Permanent } \\
\text { tion Areas }\end{array}$ & \\
\hline & Legal Reserve areas & \\
\hline & River Sources & \\
\hline
\end{tabular}

Table 1. Full overview of the datasets imported into DPAT.

and restrict the PRODES-Cerrado and DETER-Cerrado layers to the selected region. The interactive box 2 organizes all layers added to the map, presenting the respective labels and legends. The interactive box 3 is responsible to show a mini report of the selected deforestation polygon, presenting the deforested area, location and other informations. This feature uses the UTFGrid service available on OWS Server, which efficiently convert geographic data, and its respective attributes, into a grid of UTF-8 character. This data is constantly requested and processed by DPAT according to the mouse movements on the map.

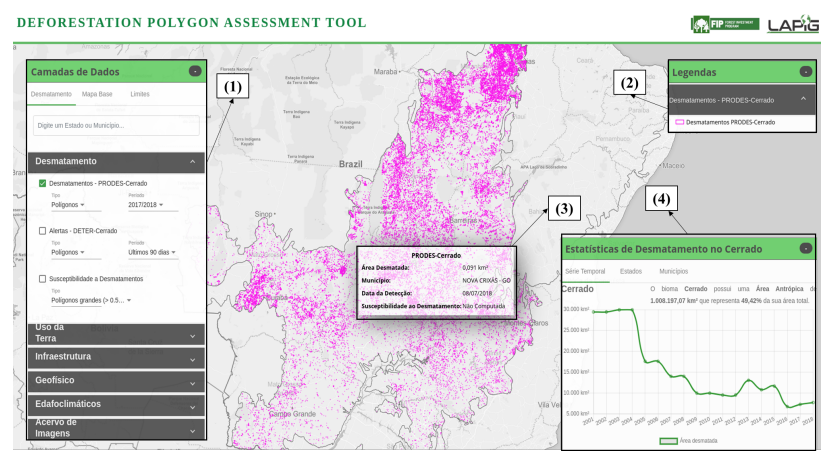

Figure 5. DPAT official initial page with its interactive map and boxes.

The interactive box 4 presents several statistical data about the PRODES-Cerrado, such as deforestation time series and a ranking of the states/municipalities with the largest deforested area. This component is automatically updated according to the selected region and/or year of PRODES-Cerrado. So far three statistical analysis have been implemented:

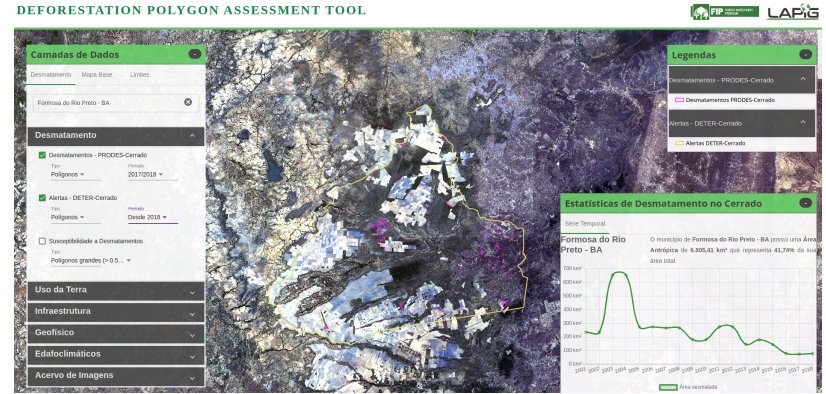

Figure 6. DPAT page presenting the PRODES-Cerrado polygons detected in 2018 properly filtered by the municipality of Formosa do Rio Preto - BA (with Sentinel image on the background).

1. Deforestation time-series: The total anthropic area and a line chart with the deforested area, in $\mathrm{km}^{2}$, for all the PRODES-Cerrado years (i.e. 2000 to 2018 - Figure 7a)

2. Deforestation by state: A bar chart with the deforested area, in $\mathrm{km}^{2}$, for all the Cerrrado states considering the selected year (Figure $7 \mathrm{p}$ ).

3. Deforestation ranking by cities: Top 10 municipalities regarding deforested area, for a given year, considering the entire Cerrado, or a selected state (Figure 7p).

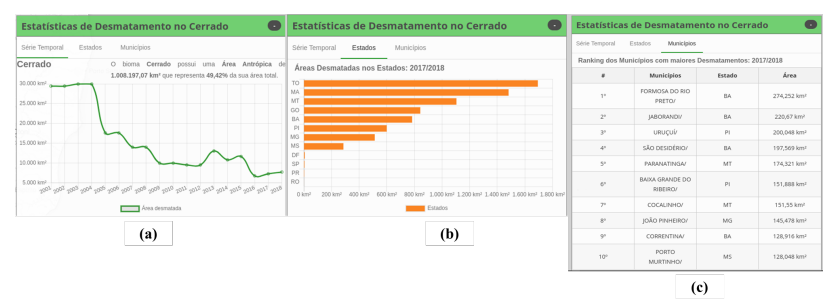

Figure 7. PRODES-Cerrado data over the years (a), ranked by state (b) and municipalities (c).

The key aspect of DPAT is the possibility to retrieve a complete report for each PRODES-Cerrado and DETER-Cerrado polygon, with several information obtained via spatial relation with other datasets. Figure 8 exemplifies the report of a PRODESCerrado polygon, detected on July 16th of 2017 in the municipality of Loreto-MA, that presents the Landsat images of deforested area, the information of the National Land Registry dataset and the results of field validation and automatic deforestation assessment.

One of the information presented in the Report is the intersection of PRODES-Cerrado or DETER-Cerrado polygon with the Rural Environmental Registry (CAR), which is an electronic registration, mandatory for all rural properties, aiming to integrate environmental information regarding the situation of Permanent Protected Areas, Legal Reserve areas, forests, native vegetation remnants and consolidated areas of Brazil's properties and rural settlements. Figure 9 presents these spatial relations allowing the verification of which rural properties are associated with the deforestation and if it occurred in a restricted area.

As previously reported, part of the project consisted of field validations, which consisted of several field trips to validate deforestation polygons. Therefore, all observations about the selected deforestation noted during the field validation are also 


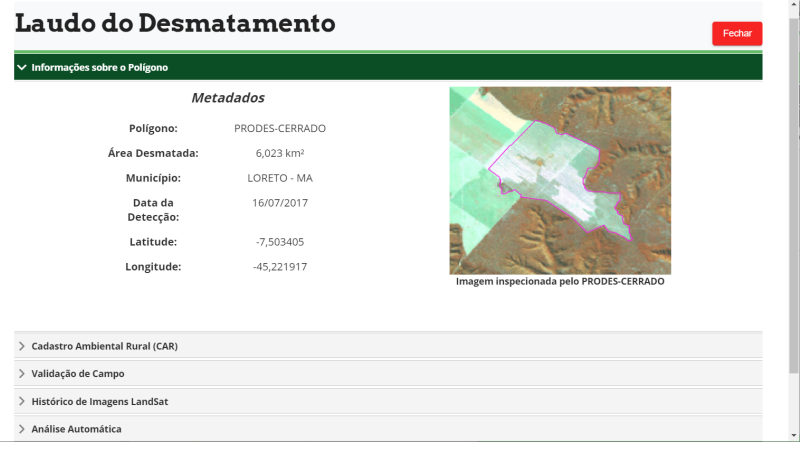

Figure 8. Initial page regarding the Deforestation Report Dialog of a selected polygon.
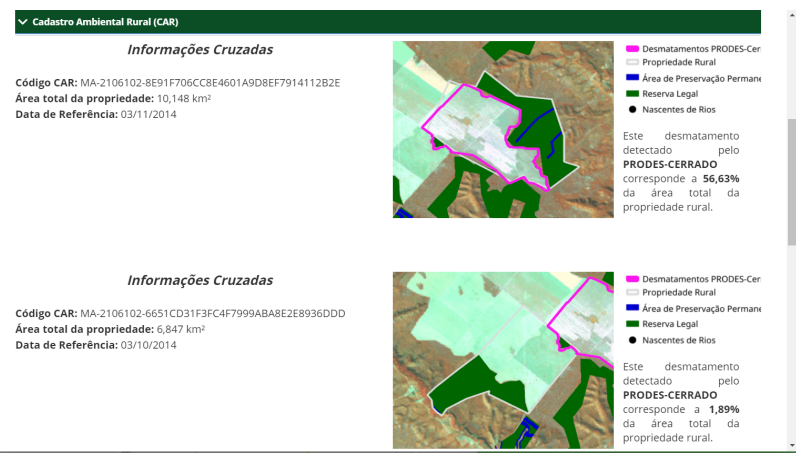

Figure 9. Deforestation Report presenting the spatial intersection of a selected deforestation polygon with the respective Rural Environmental Registry (CAR)

displayed in the Deforestation Report, as shown in figure 10 These observations includes photographs and video footage obtained through ground cameras and drone overpasses. In order to facilitate access to the field-validated polygons, it is possible to filter the deforestations displayed in the interactive map by selecting the "Polígonos validados em campo" option in the PRODES-Cerrado layer in interactive box 1, so that only PRODES-Cerrado polygons that have been physically visited are displayed on the map.

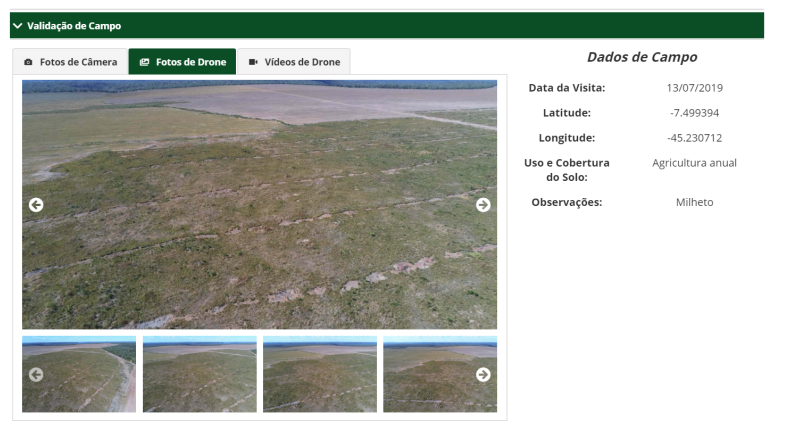

Figure 10. Deforestation Report presenting all the observations collected during the field validation.

Next, all the Landsat images from 2000 to 2018 for the selected polygon region and the consolidated land coverage by visual inspection (when available) according to INPE and LAPIG/UFG are presented (figure 11. These images and the land coverage classification were the same used during the sampling validation. However, since this phase of the project is not complete, this tab is still under development concerning the organization of data resulting from the interpreter analysis. Hopefully, this information will enable a greater understanding of the land coverage and use dynamics around the polygon area over the years.

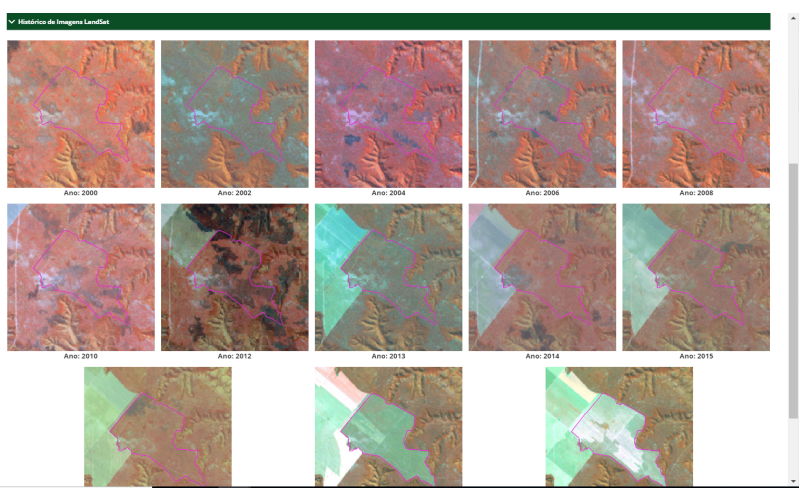

Figure 11. Deforestation Report presenting all the historical Landsat Images from 2000 until 2018 (which were used in the sampling validation).

Finally, the Deforestation Report also presents the results obtained from both methods used during the automatic validation assessment (see section 3), as presented in figure 12 Initially the PRODES-Cerrado polygon over the deforestation susceptibility layer for large deforestation and its percentage of occurrence are presented. Next, the percentage of MODIS pixels that suffered breaks in their time series (as detected by the BFastMonitor algorithm) within the PRODES-Cerrado polygon are also presented. This form of visualization optimizes the analysis of both automatic methods and their performance in automatically detecting deforestation on the PRODES-Cerrado polygon.

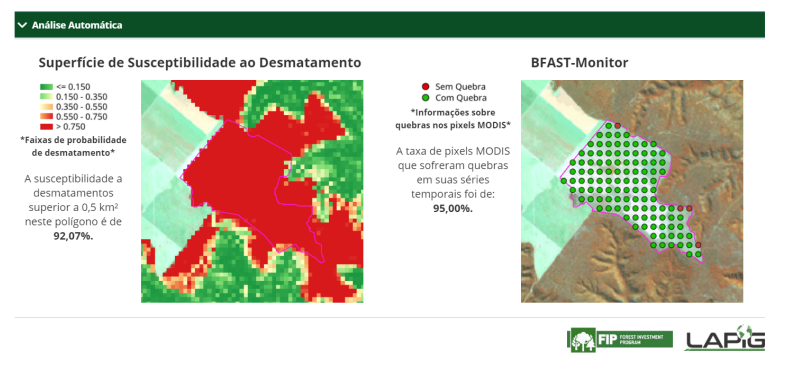

Figure 12. Deforestation Report presenting the results obtained during the automatic validation assessment.

It is noteworthy mentioning that not all polygons present every information discussed. For instance, the National Land Registry only became available in 2014, therefore only deforestation polygons detected after 2014 were spatially related. Next, the automatic validation assessment results are only displayed for 2016, 2017 and 2018 polygons, since these were the years used to assess the methods. And finally, the digital media (photos and videos) are only available for polygons that have been included in the Field Validation.

\section{CONCLUDING REMARKS}

In this work we presented the Deforestation Polygon Assessment Tool-DPAT, a web-based platform to provide context information and estimate the uncertainty regarding the polygons 
produced by the PRODES-Cerrado and DETER-Cerrado, using field validation and automatic deforestation assessments. According to our field validation, $98 \%$ of the visited areas were anthropized and, in general, our automatic deforestation assessments (i.e. via BfastMonitor and Weights of Evidence) presented a good convergence with the PRODES-Cerrado and DETER-Cerrado data. These results and other key datasets are publicly available at DPAT, which have several implemented functionalities to visualize and analyse the deforestation in the Cerrado biome. Further investigations will be necessary to define how these results and analysis will be combined to generate a uncertainty level for the deforestation and alerts polygons. The Deforestation Report will be improved by new spatial relations with the National Land Registry data, in order to verify the proportion of deforested area that occurred within the legal reserves and permanent protected areas. In addition, a printing functionality will be implemented to assist the government agencies in monitoring and combating deforestation by field actions.

\section{ACKNOWLEDGEMENTS}

This work, part of the Development of Systems to Prevent Forest Fires and Monitor Vegetation Cover in the Brazilian Cerrado Project (FIP Cerrado), was supported by The World Bank, the Brazilian Research Council (CNPq) and the Coordination for the Improvement of Higher Education Personnel (CAPES).

\section{REFERENCES}

Assis, F., Fernando, L., Ferreira, K. R., Vinhas, L., Maurano, L., Almeida, C., Carvalho, A., Rodrigues, J., Maciel, A., Camargo, C., 2019. TerraBrasilis: A Spatial Data Analytics Infrastructure for Large-Scale Thematic Mapping. ISPRS International Journal of Geo-Information, 8(11), 513.

Azevedo, A. A., Rajão, R., Costa, M. A., Stabile, M. C., Macedo, M. N., dos Reis, T. N., Alencar, A., Soares-Filho, B. S., Pacheco, R., 2017. Limits of Brazil's Forest Code as a means to end illegal deforestation. Proceedings of the National Academy of Sciences, 114(29), 7653-7658.

Diniz, C. G., de Almeida Souza, A. A., Santos, D. C., Dias, M. C., da Luz, N. C., de Moraes, D. R. V., Maia, J. S., Gomes, A. R., da Silva Narvaes, I., Valeriano, D. M. et al., 2015. DETER-B: The new Amazon near real-time deforestation detection system. Ieee journal of selected topics in applied earth observations and remote sensing, 8(7), 3619-3628.

Foundation, O., 2019. Main page - openstreetmap foundation,. [Online; accessed 22-November-2019].

Hansen, M. C., Loveland, T. R., 2012. A review of large area monitoring of land cover change using Landsat data. Remote sensing of Environment, 122, 66-74.

Huete, A., Didan, K., Miura, T., Rodriguez, E. P., Gao, X., Ferreira, L. G., 2002. Overview of the radiometric and biophysical performance of the MODIS vegetation indices. Remote sensing of environment, 83(1-2), 195-213.

Klink, C. A., Machado, R. B., 2005. A conservação do Cerrado brasileiro. Megadiversidade, 1(1), 147-155.
Nogueira, S., Parente, L. L., Ferreira, L. G., 2018. Development of deforestation probability surface in support of the vegetagion monitoring in the brazilian cerrado biome. AGU Fall Meeting Abstracts.

OGC, 2019. Ogc standards. [Online; accessed 22-November2019].

Parente, L. L., Nogueira, S., Ferreira, L. G., 2018. Assessing land-cover changes in the brazilian cerrado biome based on the time-series analysis of modis and landsat datasets. AGU Fall Meeting Abstracts.

Sano, E. E., Rosa, R., Brito, J. L. S., Ferreira, L. G., 2008. Mapeamento semidetalhado do uso da terra do Bioma Cerrado. Pesquisa agropecuária brasileira, 43(1), 153-156.

Sano, E. E., Rosa, R., Scaramuzza, C. A. d. M., Adami, M., Bolfe, E. L., Coutinho, A. C., Esquerdo, J. C. D. M., Maurano, L. E. P., Narvaes, I. d. S., Oliveira Filho, F. J. B. d. et al., 2019. Land use dynamics in the Brazilian Cerrado in the period from 2002 to 2013. Pesquisa Agropecuária Brasileira, 54.

Scaramuzza, C. d. M., Sano, E., Adami, M., Bolfe, E., Coutinho, A., ESQUERDO, J., MAURANO, L., NARVAES, I. d. S., de OLIVEIRA FILHO, F., ROSA, R. et al., 2017. Landuse and land-cover mapping of the Brazilian cerrado based mainly on Landsat-8 satellite images. Área de Informação da Sede-Artigo em periódico indexado (ALICE).

Silva, W. C., Ferreira, M. E., Teixeira, L. M. S., Malaquias, F. S. S., Parente, L. L., Ferreira, L. G., 2017. PLATAFORMA LIVRE E INTERATIVA DE MAPAS PARA A GESTÃO TERRITORIAL E AMBIENTAL DO BIOMA CERRADO. Revista Brasileira de Cartografia, 69(8).

Soares-Filho, B., Rodrigues, H., Costa, W., 2009. Modeling environmental dynamics with Dinamica EGO (guidebook). Belo Horizonte: IGC/UFMG: Universidade Federal De Minas Gerais.

Strassburg, B. B., Brooks, T., Feltran-Barbieri, R., Iribarrem, A., Crouzeilles, R., Loyola, R., Latawiec, A. E., Oliveira Filho, F. J., Scaramuzza, C. d. M., Scarano, F. R. et al., 2017. Moment of truth for the Cerrado hotspot. Nature Ecology \& Evolution, 1(4), 0099.

The World Bank, 2016. Brazil - Development of Systems to Prevent Forest Fires and Monitor Vegetation Cover in the Brazilian Cerrado Project.

Valeriano, D. M., Mello, E. M., Moreira, J. C., Shimabukuro, Y. E., Duarte, V., Souza, I., Santos, J., Barbosa, C. C., Souza, R., 2004. Monitoring tropical forest from space: the PRODES digital project. International Archives of Photogrammetry Remote Sensing and Spatial Information Sciences, 35, 272-274.

Verbesselt, J., Zeileis, A., Herold, M., 2012. Near real-time disturbance detection using satellite image time series. Remote Sensing of Environment, 123, 98-108. 